\title{
Natural radioactivity investigation in Dam sediments of northeast Algeria using gamma spectroscopy
}

\author{
Fatima Benrachi ${ }^{1 *}$, Ghania Bouhila $^{1}$, Asma Saadi ${ }^{1}$, and Mourad Ramdhane ${ }^{2}$ \\ ${ }^{1}$ LPMS Laboratory, Frères Mentouri Constantine 1 University, 25000 Constantine, Algeria \\ ${ }^{2}$ LPSC, Université Grenoble Alpes, CNRS/IN2P3, Institut Nationale Polytechnique de Grenoble, F-38026 Grenoble Cedex France
}

\begin{abstract}
Current research paper intends to estimate the natural radioactivity levels in sediments samples collected from Beni Haroun Dam in the northeast Algeria, using high resolution HPGe detector. The mean activity concentrations values measured for the radionuclides ${ }^{232} \mathrm{Th},{ }^{226} \mathrm{Ra}$ and ${ }^{40} \mathrm{~K}$ are $18.9 \pm 1.9,37.3 \pm 2.7$ and $149.9 \pm 5.5 \mathrm{~Bq} / \mathrm{kg}$, respectively. The ${ }^{137} \mathrm{Cs}$ anthropogenic radionuclide has been observed with maximum activity concentration value of $0.8 \pm 0.4 \mathrm{~Bq} / \mathrm{kg}$, which is considered an insignificant amount. In order to assess the radiological threat of gamma radiations emitted by these radionuclides on the health of the population, absorbed dose rate, annual effective dose equivalent and radiation hazard indices were had been calculated. The obtained values are compared with the world wide average ones.
\end{abstract}

\section{Introduction}

Every living creature in the environment is exposed to ionizing radiation comes from natural and anthropogenic radionuclides. Most of natural radioactivity present in environment arises from radioactive isotopes of ${ }^{40} \mathrm{~K},{ }^{238} \mathrm{U}$ and ${ }^{232} \mathrm{Th}$ decay series $[1,2]$. The specific levels of natural environmental radiation are related to the composition of each lithologically area, and to the contents of the rocks from which the sediments or soils originate [3]. Furthermore, radiations originating from anthropogenic activities like nuclear weapons testing, diagnostic and therapeutic medicine, and radiation from nuclear plants can also released large amounts of radionuclides such ${ }^{137} \mathrm{Cs}$ in environment [4]. Natural sources make up approximately $80 \%$ of the total radiation dose which a person is exposed to in a year, while $20 \%$ come from anthropogenic sources [5]. Thus, the determination of distributions of the terrestrial and anthropogenic radionuclides in soil and sediment is of great interest for many researchers in the world [2-4]. In this work, the study area was Beni Haroun Dam, which located at $36^{\circ} 33^{\prime} 19^{\prime \prime}$ N $6^{\circ} 16^{\prime} 11^{\prime}$ ' E, North-Eastern of Algeria. The aim of this study is to evaluate the ${ }^{238} \mathrm{U}$, ${ }^{232} \mathrm{Th},{ }^{40} \mathrm{~K}$ and ${ }^{137} \mathrm{Cs}$ radionuclide concentrations to provide background data on natural and artificial radioactive isotopes for the studied region, using gamma-ray spectrometry in low background configuration.

Additionally, an assessment of the radiological risks on humans arising from radioactivity sediment samples was determined in terms of the radiological parameters: the absorbed dose rate (D), the annual effective dose equivalent (AED) and radiation hazard indices were had been calculated. The obtained values are compared with the world wide average ones.

\section{Materials and methods}

\subsection{Study area}

Beni Haroun Dam, constructed in August 2003, is the largest dam in Algeria, located in northeast of Algeria, at about $15 \mathrm{~km}$ of the Mila city. The artificial dam was built at the confluences of Oued Rhumel and Oued Endja to $40 \mathrm{~km}$ north of Constantine Province. The Dam covers an area of 3.929 ha and its depth is 120 meters with a capacity of 960 million cubic meters of water. It supplies five provinces with potable as well as irrigation water $[6$, 7].

\subsection{Sample collection and preparation}

Five sediment samples were collected from different locations near Beni Haroun Dam, at a depth of 5-10 cm from the top surface layer as shown in Figure 1. Samples were crushed and dried at $110^{\circ} \mathrm{C}$ temperature in an oven until their weight become constant. Then, they were sieved to fine powder, passed through a standard $1 \mathrm{~mm}$ mesh size and sealed into small cylindrical plastic containers having the same geometry as detector. Before measurements, the containers were stored approximately for 4 weeks $(\sim 7$ half-lives) to reach secular equilibrium

Corresponding author: fatima.benrachi@umc.edu.dz 
between the ${ }^{238} \mathrm{U}$ and ${ }^{232} \mathrm{Th}$ series and their respective progeny $[8,9]$.

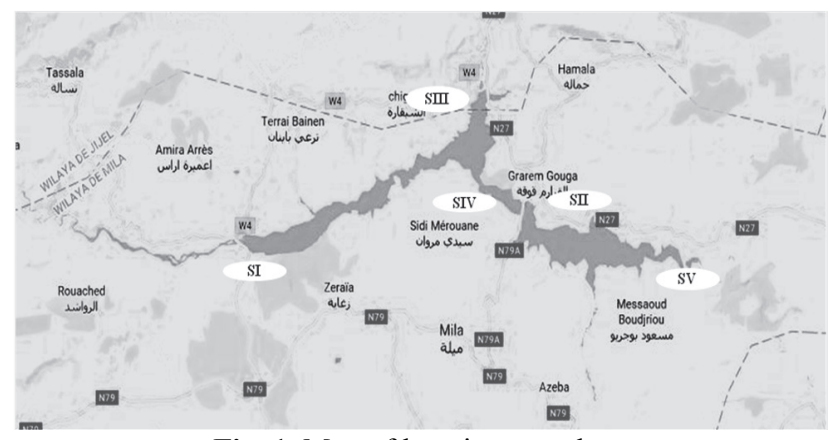

Fig. 1. Map of location samples

\subsection{Gamma ray spectrometric analysis}

The activity concentrations of samples were measured at low activity laboratory (LBA/LPSC-Grenoble) which has two HPGe detectors. Both detectors are surrounded by $2 \mathrm{~cm}$ of archeological lead and by $15 \mathrm{~cm}$ of purified lead. The two detectors and the lead plate are placed at the center of a two-meter-high cube; each face of this cube being constituted with a liquid scintillation detector. These detectors proceed as dynamic veto stopping the acquisition of data during the passage of a cosmic ray. The data acquisition and analysis use two PCs equipped with the "Interwinner" (ITECHinstruments) software. The detectors have a relative efficiency of $20 \%$ and the energy resolution was of 0.78 and $1.85 \mathrm{keV}$ at $122 \mathrm{keV}\left({ }^{57} \mathrm{Co}\right)$ and $1332 \mathrm{keV}\left({ }^{60} \mathrm{Co}\right)$ gamma lines, respectively [10]. IAEA-RGU-1 and IAEA-RGTh-1, in powder form, installed in the same position and plastic bottle as the samples, were used to determine the detectors efficiency curves. The activities of the natural-series were $4940 \pm 30 \mathrm{~Bq} / \mathrm{kg}$ for ${ }^{238} \mathrm{U}$ and $228 \pm 2 \mathrm{~Bq} / \mathrm{kg}$ for ${ }^{235} \mathrm{U}$ in IAEA-RGU-1 and $3250 \pm 10$ $\mathrm{Bq} / \mathrm{kg}$ for ${ }^{232} \mathrm{Th}$ in IAEA-RGTh-1 [11]. Each sample was measured for 48 hours. The measured prominent gamma-ray lines from both the Uranium and Thorium decay series and ${ }^{40} \mathrm{~K},{ }^{137} \mathrm{Cs}$ (Table 1) were used for sample analysis to determine the activity concentrations after correcting by background counts.

Table 1: Prominent gamma energy used for estimation of radionuclides actvity

\begin{tabular}{|c|c|c|c|c|c|}
\hline $\begin{array}{c}\text { Radio } \\
\text { nuclide }\end{array}$ & $\begin{array}{c}\text { Energy } \\
\text { (keV) }\end{array}$ & $\begin{array}{c}\text { Gamma- } \\
\text { ray } \\
\text { intensity } \\
\text { (\%) }\end{array}$ & $\begin{array}{c}\text { Radio } \\
\text { Nuclide }\end{array}$ & $\begin{array}{c}\text { Energy } \\
\text { (keV) }\end{array}$ & $\begin{array}{c}\text { Gamma } \\
\text {-ray } \\
\text { intensity } \\
\text { (\%) }\end{array}$ \\
\hline${ }^{238} \mathrm{U}$ series & & & ${ }^{232} \mathrm{Th}$ series & & \\
${ }^{234} \mathrm{Th}$ & 63.29 & 4.80 & ${ }^{228} \mathrm{Ac}$ & 911.2 & 25.80 \\
${ }^{214} \mathrm{~Pb}$ & 351.93 & 37.60 & ${ }^{212} \mathrm{~Pb}$ & 238.6 & 43.30 \\
${ }^{214} \mathrm{Bi}$ & 609.31 & 46.10 & ${ }^{212} \mathrm{Bi}$ & 727.3 & 6.58 \\
${ }^{210} \mathrm{~Pb}$ & 46.54 & 4.10 & ${ }^{208} \mathrm{Tl}$ & 583.1 & 30.30 \\
${ }^{40} \mathrm{~K}$ & 1460.8 & 10.72 & ${ }^{137} \mathrm{Cs}$ & 661.6 & 85.10 \\
\hline
\end{tabular}

\section{Results and discussion 3.1 Estimation of activity concentrations}

In The activity concentrations for the radionuclides in the five measured samples were evaluated using the relation:

$$
A_{s}=\frac{N_{E}}{\varepsilon_{E} p t m}
$$

Where: $N_{E}$ and $\varepsilon_{E}$ are the net peak area and the detection efficiency at energy $\mathrm{E}, p$ is the branching ratio of radionuclide of interest; $t$ is the counting time $(\mathrm{s}) ; m$ is the mass of the measured sample in $\mathrm{kg}$.

The results of the concentration values of activity ${ }^{226} \mathrm{Ra},{ }^{232} \mathrm{Th},{ }^{40} \mathrm{~K}$ and ${ }^{137} \mathrm{Cs}$ reported in Figure 2 show an inhomogeneous distribution of the elements. This difference is probably due to the variation in the geological composition of the various sites near the dam from which the samples were taken. The ${ }^{40} \mathrm{~K}$ is the largest contributor to the total activity of all samples. This is explained by the presence of the clay in all the places of the dam, because the clays contain a relatively high concentration of potassium. On the other hand, the activity of ${ }^{226} \mathrm{Ra}$ is higher than that of ${ }^{232} \mathrm{Th}$ in almost all samples, this could be related to the difference of their solubility in the natural environment. From this figure, the average activities of ${ }^{226} \mathrm{Ra},{ }^{232} \mathrm{Th}$ and ${ }^{40} \mathrm{~K}$ obtained in the study are below the global average of 35, 33 and 400 $\mathrm{Bq} / \mathrm{kg}$ as reported by UNSCEAR [5]. The ${ }^{137} \mathrm{Cs}$ anthropogenic radionuclide has been observed with maximum activity concentration value of $0.8 \pm 0.4$ $\mathrm{Bq} / \mathrm{kg}$, which is considered an insignificant amount.

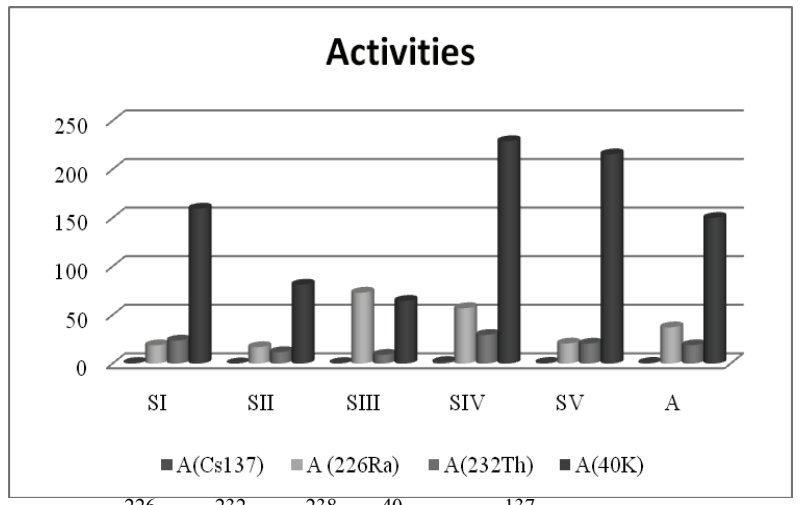

Fig. 2.: ${ }^{226} \mathrm{Ra},{ }^{232} \mathrm{Th},{ }^{238} \mathrm{U},{ }^{40} \mathrm{~K}$ and ${ }^{137} \mathrm{Cs}$ activities in five sediment samples

\subsection{Estimation of gamma radiation dose rates}

The absorbed dose rate in air at $1 \mathrm{~m}$ above the ground surface and the annual effective dose equivalent for the adults from outdoor gamma radiation were calculated using the following formula Eq. 2 and 3 [5]:

$$
\begin{gathered}
\mathrm{D}(\eta \mathrm{Gy} / \mathrm{h})=0.462 \mathrm{~A}_{\mathrm{Ra}}+0.621 \mathrm{~A}_{\mathrm{Th}}+0.0417 \mathrm{~A}_{\mathrm{K}} \\
\mathrm{AED}(\mu \mathrm{Sv} / \mathrm{y})=\mathrm{D}(\eta \mathrm{Gy} / \mathrm{h}) \times 8760 \mathrm{~h} \times 0.2 \times 0.7 \mathrm{~Sv} / \mathrm{Gy} \times 10^{-3}(3)
\end{gathered}
$$

Figure 3 and 4 show the calculation results of absorbed dose and annual effective dose equivalent, respectively. Their mean values were found to be $35 \eta G y h^{-1}$ and 43 $\mu \mathrm{svy}^{-1}$, which are lower in comparison with the world average value, which equal to $59 \eta G y h^{-1}, 70 \mu_{\mathrm{svy}}{ }^{-1}$, respectively [5]. 


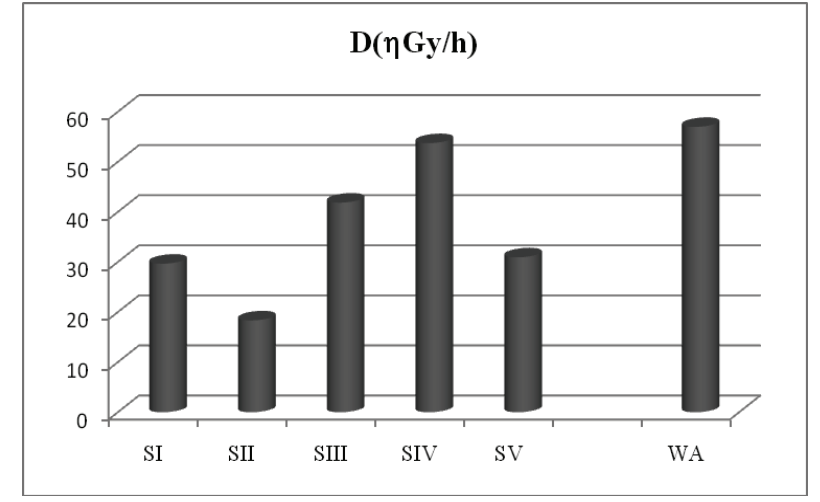

Fig. 3.: Absorbed dose rate of sediment samples

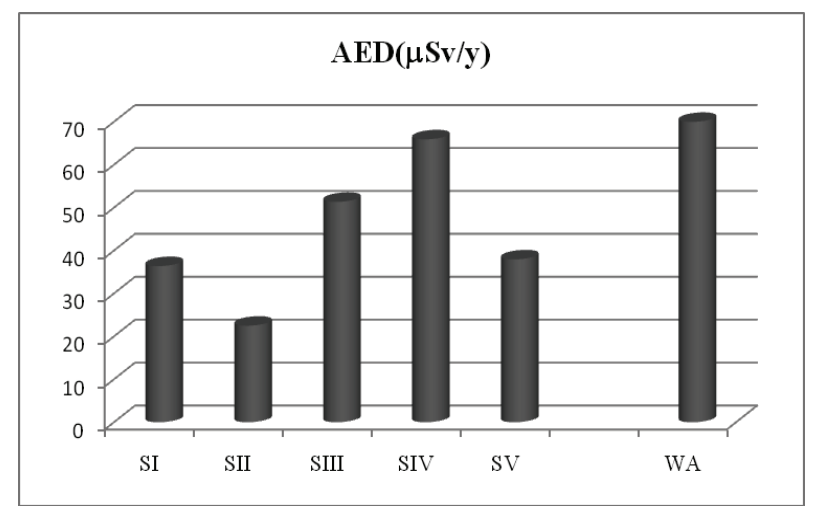

Fig. 4. Annual effective dose of sediment samples

\subsection{Estimation of Radiation hazard indices}

Besides, the results were evaluated in terms of the radiation hazard by means of the radium equivalent activity $\left(\mathrm{Ra}_{\mathrm{eq}}\right)$ which is calculated through the relation given by [12].

$$
\mathrm{Ra}_{\mathrm{eq}}=0.077 \mathrm{~A}_{\mathrm{K}}+1.43 \mathrm{~A}_{\mathrm{Th}}+\mathrm{A}_{\mathrm{Ra}}
$$

The $\mathrm{Ra}_{\mathrm{eq}}$ values for investigated locations are shown in Table 2. In addition, $\mathrm{H}_{\text {ex }}$ and $\mathrm{H}_{\text {in }}$ indices were calculated by means [12]:

$$
\begin{aligned}
& \mathrm{H}_{\text {ex }}=\frac{\mathrm{A}_{\mathrm{Ra}}}{370}+\frac{\mathrm{A}_{\mathrm{Th}}}{259}+\frac{\mathrm{A}_{\mathrm{K}}}{4810} \\
& \mathrm{H}_{\text {in }}=\frac{\mathrm{A}_{\mathrm{Ra}}}{185}+\frac{\mathrm{A}_{\mathrm{Th}}}{259}+\frac{\mathrm{A}_{\mathrm{K}}}{4810}
\end{aligned}
$$

In the Table 2, the values of $\mathrm{H}_{\mathrm{ex}}$ and $\mathrm{H}_{\mathrm{in}}$ indices values range from 0.11 to 0.32 and 0.15 to 0.47 respectively. The $\mathrm{Ra}_{\mathrm{eq}}, \mathrm{H}_{\mathrm{ex}}$ and $\mathrm{H}_{\mathrm{in}}$ values in the study area are below than their permissible limits, which indicate that the sediments do not pose any significant radiation hazard.
Table 2. Radiation hazard indices for investigation samples.

\begin{tabular}{cccc}
\hline \multirow{2}{*}{ Locations } & \multicolumn{3}{c}{ Radiation hazard indexes } \\
\cline { 2 - 4 } & $\mathbf{R a}_{\text {eq }}\left(\mathbf{B q ~ k g} \mathbf{~ k g}^{-1}\right)$ & $\mathbf{H}_{\text {ex }}$ & $\mathbf{H}_{\text {in }}$ \\
\hline SI & $65.03 \pm 1.31$ & $0.18 \pm 0.01$ & $0.23 \pm 0.06$ \\
SII2 & $66.64 \pm 0.95$ & $0.18 \pm 0.01$ & $0.24 \pm 0.06$ \\
SIII & $40.10 \pm 0.53$ & $0.11 \pm 0.01$ & $0.15 \pm 0.03$ \\
SIV & $90.90 \pm 1.57$ & $0.25 \pm 0.01$ & $0.44 \pm 0.04$ \\
SV & $116.95 \pm 1.45$ & $0.32 \pm 0.01$ & $0.47 \pm 0.05$ \\
Mean & $75.93 \pm 3.90$ & $0.21 \pm 0.21$ & $0.31 \pm 0.25$ \\
Value & & & \\
\hline
\end{tabular}

\section{Conclusion}

Natural radioactivity concentrations of ${ }^{226} \mathrm{Ra},{ }^{232} \mathrm{Th}$ and ${ }^{40} \mathrm{~K}$ have been measured in sediment samples collected from different locations around Beni haroun Dam in the northeast Algeria, using high resolution HPGe detector. Then, the gamma radiation dose rates values are estimated. The results indicate that the mean activity levels of radionuclides in all samples are within the world average values reported by UNSECEAR [5]. Moreover, the calculated values of absorbed dose rate, annual effective dose equivalent and radiation hazard indices were found under their permissible limits. The ${ }^{137} \mathrm{Cs}$ anthropogenic radionuclide has been observed with an insignificant amount. The present study was carried out to give a baseline reference data.

Authors of this article thanks the organizers of the $3^{\text {rd }}$ International Conference on Theoretical and Experimental studies in nuclear applications and technology 10-12 May 2017 Adana-Turkey for the organization and the support provided during the conference.

\section{References}

1. X. Lu, X. Zhang, F. Wang, Environ. Geol. 53, 1475 (2008).

2. A. Khatir Sam et al., Radiat. Prot. Dosim. 71(2), 141 (1997).

3. M. Mohery, Shadiah Baz, Adel M. Kelany, A.M. Abdallah. Rad. Phys. Chem. 97, 16 (2014).

4. E.O. Agbalagba, G.O. Avwiri, Y.E. Chad-Umoreh. J. Environ. Rad. 109, 64 (2012).

5. United Nations Scientific Committee on the Effects of Atomic Radiation (UNSCEAR), Sources and Effects of Ionizing Radiation (Report to the General Assembly) (New York: United Nation) (2000).

6. R. Marmi, M. Kacimi, M. Boularek, Revista de geomorfologie, 10, 51 (2008).

7. A. Mebarki, Ressources en eau et aménagement en Algérie. Le bassin du Kébir-Rhumel. Alger, Office des Publications Universitaires (1984).

8. T. Santawamaitre et al., J. Environ. Rad. 138, 80 (2014).

9. A. Nada et al., Appl. Radiat. Isot. 67, 643 (2009)

10. http://1psc.in2p3.fr.

11. Preparation of gamma-ray spectrometry reference materials RGU-1, RGTh-1 and RGK-1 report-AIEA /RL/148, Vienna, 1987

12. J. Beretka, P. J. Mathew, Health Phys. 48, 87 (1985). 